\title{
Simulating floods in urban watersheds: hydrodynamic modelling of macro, micro-drainage and flows over streets
}

\author{
M. G. Miguez, F. C. B. Mascarenhas, J. H. A. Prodanoff \\ \& L. P. C. Magalhães \\ Computational Hydraulics Laboratory, \\ Federal University of Rio de Janeiro, Brazil
}

\begin{abstract}
Floods in urban environments generally require a different mathematical treatment in order to achieve an adequate simulation technique. When dealing with these river catchments, it must be taken into account a set of features that distinguish such phenomena from rural basin flood flow simulations. It is quite usual that rainfall run-off spills out of the macro-drainage net, causing inundation at urban landscapes, like streets, squares, parks and so on. The hydrodynamic modelling in such situations must go towards a systemic approach. Several models available nowadays focus mainly on the macro-drainage net, evaluating only its capacity to convey flows resulting from heavy rainfalls. Usually, these models are not able to simulate the hydraulic behaviour of common urban landscapes. MODCEL is a hydraulic-hydrological distributed model that seems to apply to those situations where traditional approaches fail to simulate urban catchments flood flows. One of the major advantages of that model lies on the fact that streets may represent channels, squares and parks can be considered as water storage areas, microdrainage communicates to macro-drainage through gullies and manholes, trying to best reproduce what happens in urban watersheds subjected to flooding. In this work it is also presented a case study regarding a sub-basin in Rio de Janeiro state, Brazil. Model calibration made use of flood maps and river gauges data. The model was also validated for another rainfall input. Finally, some flood control measures were implemented in the model in order to compare results with present situation. The model showed to be a valuable tool for flood management.
\end{abstract}

Keywords: urban environment, flood management, mathematical modelling. 


\section{Introduction}

Watersheds of urban rivers tend to present large inundated zones. In general, urban floods involve a great variety of flow patterns on different hydraulic structures, acting in an integrate way on a complex surface configuration, where the city arises. Considering this context, it is possible to state that it is very difficult for managers to administrate a drainage system and deal with urban flood problems in a systemic way, when practical engineering tools are not available. In this way, there are indications for the use of a mathematical model. A practical model, fulfilling the requisites to simulate urban floods should be able to represent hydrologic and hydraulic basin processes in a distributed way. The model called MODCEL is capable to do this is. Mascarenhas and Miguez [4] presented an initial version of this model, using the concept of flow cells (Zanobetti et al. [2]). This paper presents the evolution of MODCEL and a case study that shows it as an urban flood management tool.

\section{MODCEL}

MODCEL is an integrated model, which conjugates a hydrological distributed model with a hydraulic-hydrodynamic looped net flow, in a spatial threedimensional representation. In this context, it is possible to say that MODCEL is a hydrological-hydraulic pseudo 3D-model. In fact, all mathematical relations written for this model are one-dimensional. The pseudo $3 \mathrm{D}$ representation is achieved by hydraulically linking vertically two different layers of flow: a superficial one, corresponding to free surface channels and flooded areas; and a subterranean one, related to free surface or drowned flow in galleries

\subsection{Hypotheses for the mathematical model}

Watershed modelling is achieved by the definition of a set of linked homogeneous compartments, called flow cells, which can be posed together in order to provide a topographic and hydraulic spatial representation. The proposed model performs an articulation of the cells in a looped form, allowing discharges to occur in different directions in a flow net over the modelled watershed. In a cell, free surface profile and water storage are assumed to be directly related to the water level at the cell centre: In this context, mass conservation law is applied to all cells and each of them receives a precipitation contribution and performs rainfall-runoff transformation. Cells are then arranged in a topological scheme, constituted by formal groups, where a cell of a particular group can only be linked either to cells in the same group or to cells of the preceding and/or the following groups. This allows the use of the double sweep method as a numerical solution. Flow between cells can be evaluated through known hydraulic laws, such as Saint-Venant dynamic equation, in its complete form or in a simplified one, the flow over free or submerged weirs equation, the flow equation through orifices, the flow equations through gullies, among others. Discharge between two adjacent cells is considered to be only function of the water levels at their centres, in any time. 


\subsection{Urban watershed modelling through MODCEL representation}

The cells, solely as units or taken in pre-arranged sets, are capable to represent the watershed scenery, composing more complex structures. On the other hand, the definition of a set of varied flow type links, which represent different hydraulic laws, allows the simulation of several flow patterns that can occur in an urban landscape. Therefore, the task related to the topographic and hydraulic modelling depends on a pre-defined set of cell types and the set of possible links between cells.

The pre-defined set of cell types considered in MODCEL is listed below:

- River or channel cells - this kind of cells is used to model the main free open channel drainage flow, in which the cross section is taken as rectangular and may be simple or compound;

- Underground gallery cells - act as complements to the drainage net;

- Urbanized superficial cells - are used to represent free surface flow over urban floodplains, as well as for storage areas linked to each other by streets. These cells present a gradation level degree for the compound rectangular cross section, assuming a certain pre-defined urbanizing pattern. Superficial cells can also represent slope areas, with little storage capacity or they can simulate a broad crested weir to the spilled waters from a river to its neighbour streets.

- Natural superficial cells - these cells are similar to the preceding case, however having prismatic shape without accepting any kind of urbanization.

- Reservoir cells - used to simulate water storage in a temporary pond or reservoir, which presents a curve for the elevation versus surface area. The reservoir type cell plays the role of damping an inflow discharge.

\subsection{Hydrological model}

Rainfall-runoff separation was originally represented in MODCEL (Mascarenhas and Miguez [1]) by applying a runoff coefficient, considered according each cell land use characteristics. Thus, for a given time interval, the effective rainfall in any cell could be obtained multiplying its runoff coefficient by the rainfall occurred in that time interval.

Aiming the improvement of the hydrological model capability regarding flood generation in the flow cell model, it was developed a simple hydrological model to represent infiltration, vegetal interception and depressions retention, being the two latter considered in a combined way in an abstraction parcel. Abstraction losses occur until this reservoir gets full. On the other hand, the infiltration can occur as long as there is water accumulated over the surface of the modelled cell. At every time step, the calculations related to the hydrologic model routines are performed and then routing is done through the hydrodynamic routines. 


\subsection{Hydrodynamic model}

The hydrodynamic model uses the conservation mass law and hydraulic and hydrodynamics relations as the core engine of MODCEL. The water level variation in a cell $i$, at a time interval $t$, is given by the continuity equation as stated in eqn (1).

$$
A_{S_{i}} \frac{d Z_{i}}{d t}=P_{i}+\sum_{k} Q_{i, k}
$$

where:

$Q_{i, k}$ is discharge between neighbours cells $\mathrm{i}$ and $\mathrm{k} ; Z_{i}$ is the water surface level at the centre of the cell i; $A_{S_{i}}$ is the water surface area for the cell $\mathrm{i} ; P_{i}$ is the discharge related to the rainfall over the cell; and $t$ is an independent variable related to time.

\subsubsection{River/channel link}

This type of link is related to river and channel flows. It may eventually also be applied to flow on the streets. More specifically, it corresponds to the free surface flow represented by the Saint-Venant dynamic equation. Here it is considered that the flow velocity time variation is much larger than the spatial one, in such a way that the velocity derivative with respect to the longitudinal distance can be neglected. Eqn (2) results from the consideration of rectangular cross section and fixed bottom (Cunge et al. [3]).

$$
\frac{1}{A_{i, k}} \frac{\partial Q_{i, k}}{\partial t}-\frac{Q B_{i, k}}{A_{i, k}^{2}} \frac{\partial Z}{\partial t}+g \frac{\partial Z}{\partial x}+g S_{f}=0
$$

where:

$B_{i, k}$ is the surface flow width between cells $\mathrm{i}$ and $\mathrm{k} ; A_{i, k}$ is the wetted flow crosssection area between cells i and $\mathrm{k} ; S_{f}$ is the energy line slope; $R_{i, k}$ is the hydraulic radius of the flow cross-section between cells $\mathrm{i}$ and $\mathrm{k} ; n$ is Manning's roughness coefficient; and $x, t$ are independent space and time variables.

The parameters $n, A_{i, k}$ and $R_{i, k}$, representative of the flow section between cells $\mathrm{i}$ and $\mathrm{k}$, are evaluated through a weighting procedure between the water levels of cells $\mathrm{i}$ and $\mathrm{k}$, here assigned as $Z_{p}$. Approximating the derivatives by finite differences and doing $S_{f}=\frac{Q_{i, k}^{2} n^{2}}{A_{i, k}^{2} R_{i, k}^{4 / 3}}$, one has:

$$
\begin{aligned}
& \frac{1}{A_{i, k}^{t}} \cdot\left[\frac{Q_{i, k}^{t}-Q_{i, k}^{t-1}}{\Delta t}\right]-\frac{Q_{i, k}^{t} \cdot B_{i, k}^{t}}{\left[A_{i, k}^{t}\right]^{2}} \cdot\left[\frac{Z_{p}^{t}-Z_{p}^{t-1}}{\Delta t}\right]+ \\
& +g \frac{\left(-\left|Z_{i}^{t}-Z_{k}^{t}\right|\right)}{\Delta x}+\frac{g n^{2}}{\left[A_{i, k}^{t}\right]^{2}\left[R_{i, k}^{t}\right]^{4 / 3}} \cdot\left[Q_{i, k}^{t}\right]^{2}=0
\end{aligned}
$$


It must be stressed that the only unknown term in equation (3) is the discharge $Q_{i, k}^{t}$, which, after evaluated, will be introduced into the mass conservation equation written for $Z_{i}^{t+1}$. The value of $Z_{i}^{t}$ and the values at $t-1$ are all already known. Then multiplying equation (3) by the cross-section area between cells and developing to turn explicit the unknown discharge at time t, eqn (4) is obtained

$$
\left(\frac{g n^{2}}{A_{i, k}^{t}\left[R_{i, k}^{t}\right]^{4 / 3}}\right) \cdot Q_{i, k}^{t}{ }^{2}+\left(\frac{1}{\Delta t}-\frac{B_{i, k}^{t}}{A_{i, k}^{t}} \cdot \frac{\Delta Z_{p}^{t, t-1}}{\Delta t}\right) \cdot Q_{i, k}^{t}+\left(g A_{i, k}^{t} \frac{\left(-\left|Z_{i}^{t}-Z_{k}^{t}\right|\right)}{\Delta x}-\frac{Q_{i, k}^{t-1}}{\Delta t}\right)=0
$$

This is a second-degree equation, which can give two real roots, and needs a complementary analysis in order to characterize the result. Considering the relations shown in eqn (5), eqn (6) is written.

$$
\begin{gathered}
a=\frac{g n^{2}}{A_{i, k}^{t}\left[R_{i, k}^{t}\right]^{4 / 3}}, b=\frac{1}{\Delta t}-\frac{B_{i, k}^{t}}{A_{i, k}^{t}} \cdot \frac{\Delta Z_{p}^{t, t-1}}{\Delta t}, c=g A_{i, k}^{t} \frac{\left(-\left|Z_{i}^{t}-Z_{k}^{t}\right|\right)}{\Delta x}-\frac{Q_{i, k}^{t-k}}{\Delta t} \\
a \cdot Q_{i, k}^{t}{ }^{2}+b \cdot Q_{i, k}^{t}+c=0
\end{gathered}
$$

Eqn (6) is a typical second-degree equation, which solution is given by $Q_{i, k}^{t}=\frac{-b \pm \sqrt{b^{2}-4 . a . c}}{2 . a}$. It is needed an additional analysis of eqn (6) terms to verify the occurrence of real roots. Term " $a$ " is always positive, because it depends only on geometrical cross-section elements, on Manning coefficient and on gravity acceleration. Term " $b$ " is also always positive as $b=\frac{1}{\Delta t}\left(\frac{A_{i, k}^{t}-B_{i, k}^{t} \Delta Z_{p}^{t, t-1}}{A_{i, k}^{t}}\right)>0$, because $A_{i, k}^{t}=B_{i, k}^{t}\left(Z_{p}^{t}-Z_{0 p}^{t}\right)>B_{i, k}^{t} \Delta Z_{p}^{t, t-1}$. Term "c" may be positive or negative, depending on the situation. A value negative for "c", being "a" positive, allows real roots results; "c" positive, however, can or cannot give real roots. Therefore one must have $c<0$, assuring that $\sqrt{b^{2}-4 . a . c}>b$. Then the discharge is given by $Q_{i, k}^{t}=\frac{-b+\sqrt{b^{2}-4 . a . c}}{2 . a}$.

Generally, for all type of links and for mass balance purposes, by convention, the discharge entering into a cell is considered positive and the one that leaves the cell is taken with a negative sign.

\subsubsection{Surface link}

This type of link corresponds to the free surface flow without inertia terms, being frequent its use between superficial urbanised or natural cells. This link is used to represent flow over streets, joining inundated areas. The dynamic Saint 
Venant equation is then reduced to a simplified form, which developed in discrete terms and re-arranging leads to eqn (7).

$$
Q_{i, k}=\left(\frac{A_{i, k} R_{i, k}^{2 / 3}}{n \Delta x^{1 / 2}}\right)\left(\left|Z_{k}-Z_{i}\right|\right)^{1 / 2}
$$

\subsubsection{Gallery link}

This kind of link represents free surface flow in closed conduits, as well as under pressure flow conditions for drainage galleries, after they became drowned. Free surface flow is modelled in this case exactly as it is in surface links, using simplified Saint Venant dynamic equation. On the other hand, when galleries become full, pressure flow conditions are given by energy conservation law considerations. MODCEL considers the gallery linked by gullies to a street above it. In this situation, flow over the street occurs with free surface and the water level associated to this flow can be considered equal to the pressure flow line level for the gallery-drowned flow. Thus, using Bernoulli equation:

$$
Z_{i}+\frac{v_{i}^{2}}{2 g}=Z_{k}+\frac{v_{k}^{2}}{2 g}+S_{f} \Delta x
$$

It will be assumed that, by hypothesis, for any given time step, the discharge, between cells $\mathrm{i}$ and $\mathrm{k}$, remains constant, in such a way that $Q_{i}=Q_{k}=Q_{i, k}$. On the other hand, the value for $S_{f}$ can be obtained from the Manning equation, as suggested by Hromadka II et al. [4]. Thus, these considerations lead to eqn (9).

$$
Q_{i, k}=-\left[\frac{2 g\left(Z_{k}-Z_{i}\right)}{\frac{1}{A_{i}^{2}}-\frac{1}{A_{k}^{2}}-\frac{2 g n^{2} \Delta x}{A_{i, k}^{2} R_{i, k}^{4 / 3}}}\right]^{1 / 2}
$$

Equation (9) was developed considering cell $\mathrm{i}$ in the upstream position. An important model feature to be stressed is that if the cell $\mathrm{i}$ is located upstream, drowned, and the downstream cell $\mathrm{k}$, also drowned, has a water elevation at the surface cell, $Z_{k}$, greater than the elevation $Z_{i}$, the flow may be forced gallery upwards. It is also important to detail how the model manages the flow transition from free surface to under pressure flow. At a gallery stretch, while it does not become drowned, open channel flow equations apply. When the water level evaluated by those equations indicates a value greater then that referred to the top of the gallery, the calculated exceeding water is returned to the surface cell, through the associated gully link. From this moment on, until the gallery is drowned, the relationships developed for under pressure flow become to be valid. It must be also noticed that from the drowning of a cell gallery the gullies related to it stop to contribute with inflow. Actually, once the mass balance is done, if a drowned stretch receives more water from upstream than that released to 
downstream, this discharge difference is sent to the surface, through the modelled gullies. At this time all happens as the gully works as a spout.

\subsubsection{Inlet gallery link}

This link acts in a variable way, depending on computed flow conditions at every time step. If there is a free surface flow at the entrance of the gallery, this link acts as a channel link, with a local head loss, associated to the contraction of flow, when passing from a channel to a gallery. If the entrance is drowned, then Bernoulli equation is used, but still considering the possible occurrence of local head losses. In this case, the gallery entrance may be drowned by downstream effects or by local lack of conveyance capacity for the open channel flow that arrives to the gallery. Both situations are treated by this link in MODCEL.

\subsubsection{Outlet gallery link}

This link is analogous to the previous one, but this time the model deals with a possible expansion of flow leaving the gallery and returning to an open channel.

\subsubsection{Gallery discharge into an open channel link}

This link allows a gallery to discharge into an open channel in a condition different from a junction. In MODCEL, junctions are treated as special cells with "Y" shape, where mass balance equilibrates inflows and outflows. This gallery discharge into an open channel link is associated to galleries that arrive at river bank at a level higher than that of the river bottom, acting as free broad crested weirs, drowned weirs, or orifices, depending on water level in the channel.

\subsubsection{Broad crested weir link}

This link represents the flow over broad-crested weirs. It is used, mainly, to represent the flow between a river and its margins. The classic formula of flow over broadcrested weirs is used here; however, the coefficients of discharge must be adjusted.

\subsubsection{Orifice link}

This link represents the classic formula for flow through orifices.

\subsubsection{Gully link}

This link promotes the interface between surface and gallery cells. When not drowned, this link acts as a weir conveying flow from streets to galleries. This weir has the length of the perimeter of the gully multiplied by the number of gullies along the street modelled by the considered cell. When drowned, this link considers flow occurring through a certain number of orifices associated to the gullies in the street.

\subsubsection{Reservoir link}

This link combines an orifice, as the outlet discharge of a reservoir, with a weir, that can enter or not in charge, depending on reservoir operation. It is useful to simulate the damping effect of a reservoir, in the design condition, and to verify reservoir functioning in more severe conditions (those in which the weir begin to be used). 


\subsubsection{Stage-discharge curve link}

This link corresponds to special structures calibrated at physically reduced scales in laboratory and basically relates a discharge with a water level, in a particular equation.

\subsubsection{Pumping link}

This link allows discharges pumped from a cell to another departing from a starting pre-defined operation level.

\subsubsection{Flap gate link}

This link simulates flows occurring in the direction allowed by the flap gate opening, and can be found, normally, in regions protected by polders.

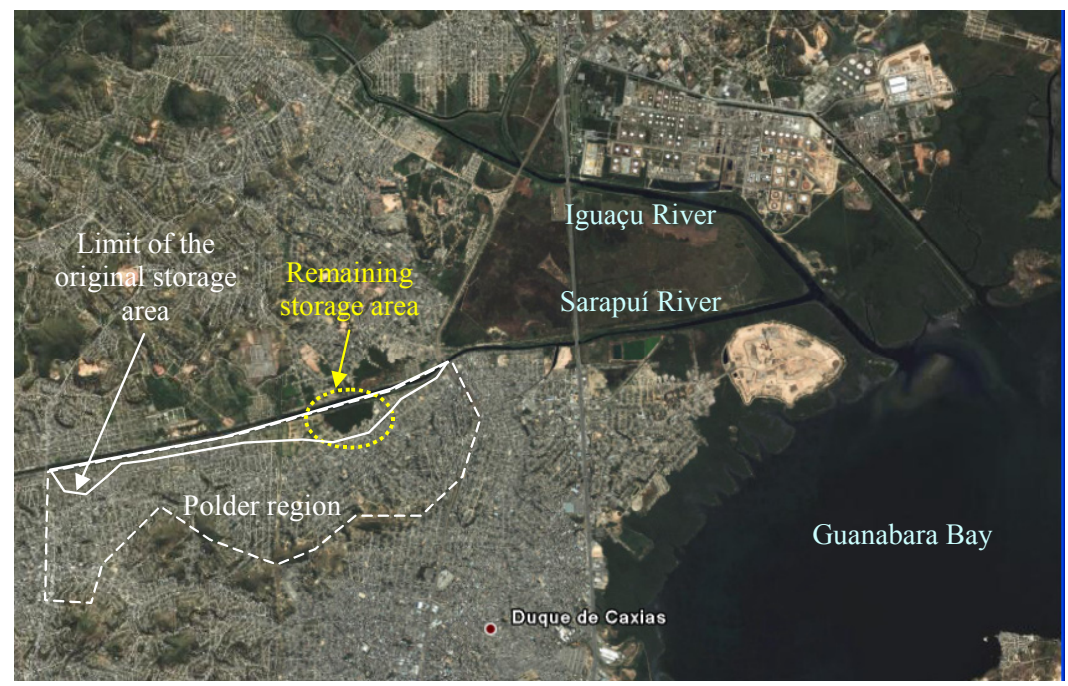

Figure 1: Aerial view of the Alberto de Oliveira Polder region.

\section{Case study}

Case study presented here refers to Alberto de Oliveira Polder, in Rio de Janeiro State, Brazil, between Duque de Caxias and Sao Joao de Meriti Cities. This polder was implemented at the right margin of Sarapuí River, in order to prevent this river to inundate local urban areas. Alberto de Oliveira Polder was adequately designed and solved the flood problem by the time of its implementation. Nowadays flood problem, however, is related to an irregular occupation of the storage area. A nonplanned process of urbanisation limited the storage area to $20 \%$ of its original size. This situation made local waters to become as hazardous as the prior main river flooding that lead to the polder solution. The case study presented in this paper makes an assessment of present situation, using MODCEL, and proposes an alternative to minimise the problem. Figure 1 shows an aerial view of the polder region, detailing the reduction of the storage area. 
The modelled region comprises a complex hydraulic system. In the upstream reach of the basin, there is a reservoir, conformed by Gericino dam, which regulates discharges of this reach. Downstream, Sarapuí River is submitted to tidal influence. There are numerous rivers and brooks. Great part of the basin is urbanised, with micro and macro-drainage interacting. The area of greater significance in this case study is protected by a polder system, but there are various flooded areas. All this diversity should be captured by model representation. Figure 2 shows a detailed sketch of the urban cell modelled area. After model calibration and validation it was produced a flooding map, for a 20 years recurrence rainfall, at polder area, combined with a 10 years recurrence rainfall, at Sarapuí river basin, as shown in figure 3. Taking into account this flooding situation, a set of proposed solutions for the region included the protection of the remaining storage area, transforming it in an environment protective area or turning it part of a new park to be built. This option should be accomplished by an increase in the number of flap gates. Complementarily, two alternative design concepts were suggested. One of them proposed a pumping station. The other, showed the need to recuperate part of the polder lost storage capacity, removing a community of a neighbourhood installed in the storage area and using a set o seven soccer fields as multifunctional landscapes. Both solutions lead to similar results in minimising floods. The inundation reduction obtained for pumping option design, considering the water level at the temporary storage area as reference, was about $52 \%$ at the cell \# 881 for instance, what was sufficient to maintain urban areas protected from inundation.

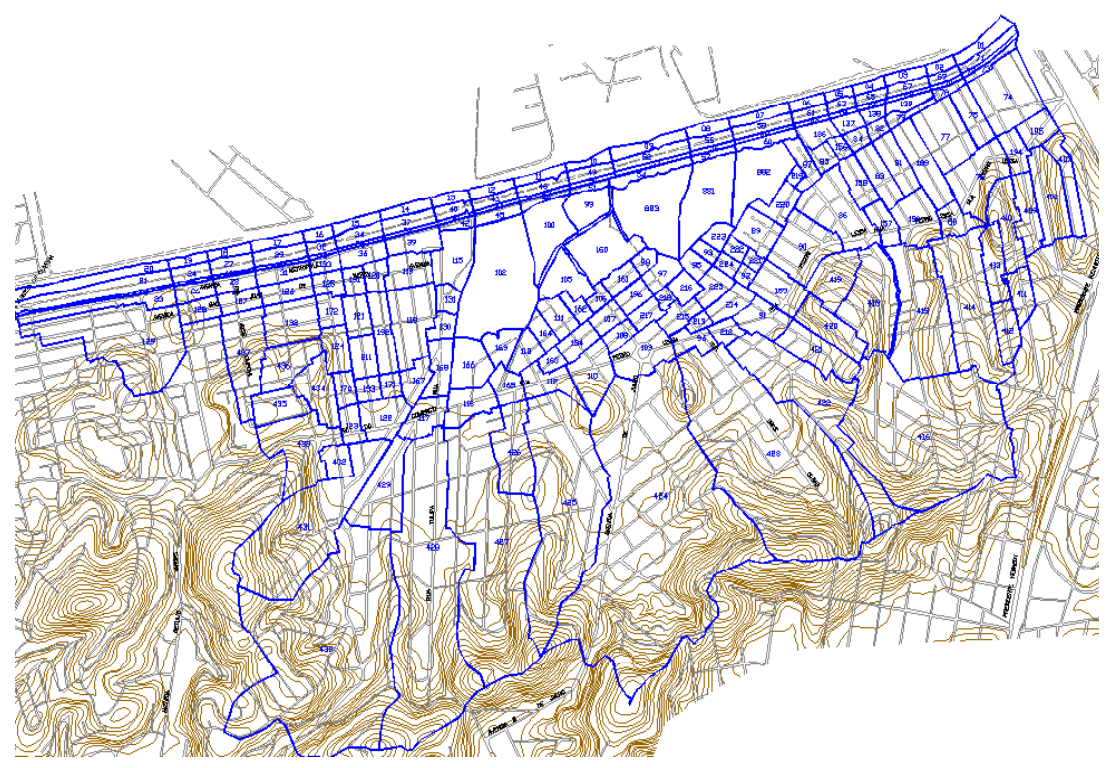

Figure 2: $\quad$ Detailed sketch of the division of the urban area modelled by cells. 


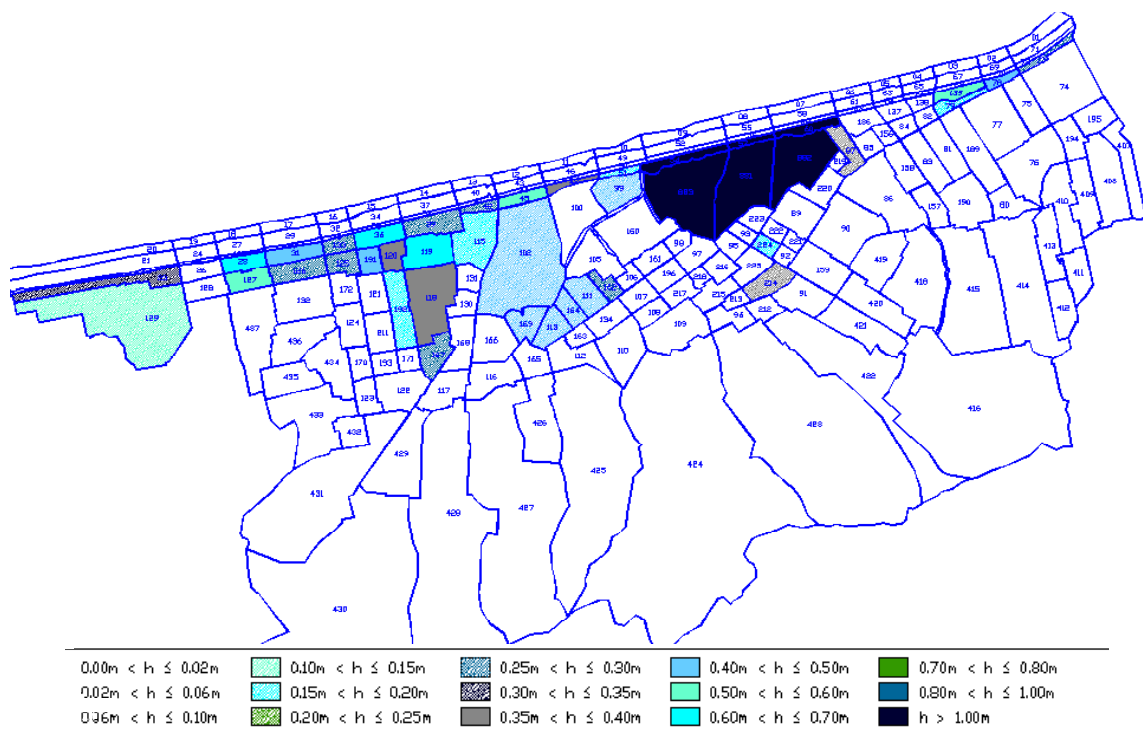

Figure 3: $\quad$ Inundation map at polder area.

\section{Conclusion}

MODCEL showed to be able to reproduce a great variety of hydraulic patterns in an urban landscape. Its ability to perform rainfall-runoff transformation, in a distributed way, allowed integrating hydrologic and hydraulic processes. The modelling of Sarapuí River basin, where it is located Alberto de Oliveira Polder, in Rio de Janeiro State, Brazil, contained the representation of a mixed rural/urban occupation, the operation of an upstream dam, a tidal influence downstream, and the operation of hydraulic structures, like flap gates and pumping stations, everything integrated in the same model. As MODCEL has a set of integrated modules, it is possible to continue to refine its capacity to represent hydraulic features by increasing types of links and cells used. MODCEL seems to be a useful tool for managing drainage systems, especially where severe flood problems occur, with large inundated areas.

\section{References}

[1] Mascarenhas, F.C.B.; Miguez, M.G.; 2002. Urban Flood Control through a Mathematical Cell. In: Water International, Vol. 27, N² 2, pg. 208-218, June 2002; Illinois, E.U.A.

[2] Cunge, J.A.; Holly Jr., F.M.; Verwey, A. . Practical Aspects of Computational River Hydraulics. London, Pitman Advanced Publishing Program, 1980.

[3] Hromadka Ii, T.V.; Clements, J.M.; Saluja, H. . Computer Methods in Urban Watershed Hydraulics. Mission Viejo, California, Lighthouse Publications, 1984.

[4] Zanobetti, D.; Lorgeré, H.; Preissman, A.; Cunge, J.A. Mekong Delta Mathematical Program Construction. Journal of the Waterways and Harbours Division, ASCE, v.96, n.WW2, p. 181-199, 1970. 